\title{
Association between Genetic Variations in Kv7.5 and Susceptibility of Lung Cancer in a Northeast Chinese Population
}

\author{
Huanrui Zhang ${ }^{1,2}$, Xuelian $\mathrm{Li}^{1,2}$, Yangwu Ren ${ }^{1,2}$, Zhihua Yin ${ }^{1,2}$, Chang Zheng ${ }^{1,2}$, \\ Xiaowei Quan ${ }^{1,2}$, Baosen Zhou ${ }^{1,2,3^{*}}$ \\ 1. Department of Epidemiology, School of Public Health, China Medical University, Shenyang, China. \\ 2. Key Laboratory of Cancer Etiology and Prevention (China Medical University), Liaoning Provincial \\ Department of Education, Liaoning, China \\ 3. Department of Clinical Epidemiology, First Affiliated Hospital, China Medical University, Shenyang, China \\ *Corresponding Author: Baosen Zhou, Department of Clinical Epidemiology, First Affiliated Hospital, \\ China Medical University, Shenyang, China.
}

\begin{abstract}
Background: The KCNQ gene family has been widely investigated in a variety of cancer cells. This study aimed to investigate the association between single nucleotide polymorphisms (SNPs) in potassium voltage-gated channel subfamily $Q$ member 5 (Kv7.5) and lung cancer risk in a Northeast Chinese population.

Methods: We conducted a hospital-based case-control study selecting 833 lung cancer cases and 641 no lung cancer controls matched by age from local hospital. The information of investigation was collected by well trained investigators through the form of interview. We used Taqman fluorescence probe method for genotyping to evaluate SNPs in Kv7.5 among 1474 subjects.

Result: The results revealed that GG genotype in $r s 4706511$ (OR=0.631, 95\%CI=0.467-0.853, $P=0.003)$ compared with AA genotype and CC genotype in rs9293902 (OR=0.654, 95\%CI=0.485-0.882 P=0.013) compared with TT genotype played significantly role in increasing risk of lung cancer.

Conclusion: These findings showed that rs4706511 and rs9293902 polymorphism might affect the susceptibility to lung cancer in a Northeast Chinese population, which might be meaningful as genetic markers for lung cancer risk.
\end{abstract}

Keywords: lung cancer; polymorphism; susceptibility; Kv7.5

\section{INTRODUCTION}

Lung cancer is one of the most common and deadliest cancers worldwide accounting for over a million people died from the disease each year[1]. The GLOBOCAN estimates for 2012 indicates that about 1.8 million cases of lung cancer are diagnosed worldwide each year, with a resulting 1.6 million deaths yearly[2]. It is well known that lung cancer is largely caused by tobacco smoking. However, not all lung cancer patients have a history of smoking, there is remaining 10-15\% of the disease occur in non-smokers in the United States (US) and European Union (EU)[3], which shows that besides tobacco, other risk factors may be involved in the etiology of lung cancer. In recent years, there is increasing evidence that the inherited genetic play a significant role in generating lung cancer[4]. Hence, it is totally considerable that lung cancer may result from genetic and environmental factors and their interactions. 
The voltage-gated potassium $(\mathrm{Kv})$ channel family is one of the largest ion channel families in the human genome[5]. It is well known that $\mathrm{Kv}$ channels are widely expressed in excitable cells where they play a fundamental role in the generation and propagation of action potentials[6]. In addition to exhibiting activation in excitable cells, $\mathrm{Kv}$ channels also exist in non-excitable cells, such as alveolar epithelial cells[7]. Unlike neurons and myocytes however, recent studies have demonstrated that several subtypes of $\mathrm{Kv}$ channels in non-excitable cells may be involved in cell migration and wound healing $[8,9]$, cell proliferation and cancer[10, 11], and apoptosis[12]. A great deal of the voltagegated potassium $(\mathrm{Kv})$ channels are considered to prompt cell proliferation[13-17], including the $\mathrm{Kv}$ channels Kv1.3, Kv1.5, Kv3.3, Kv3.4 and Kv4.1. Moreover, accumulating evidence indicates that Kv channels distributed widely in a variety of cancer cells participate in cancer development and cell proliferation. However, how various $\mathrm{Kv}$ channels affect the cell cycle and cell proliferation remains indistinct.

$\mathrm{KCNQ}$, one member of the voltage-gated potassium (Kv) channel group, encodes Kv7 channel. There are five subunits of this family, from Kv7.1 to Kv7.5, encoded by KCNQ1 to KCNQ5. Among these subunits, Kv7.1 primarily exists in cardiac cells and several epithelia[18]; four other subunits (Kv7.2-Kv7.5) are fundamentally expressed in the nervous system[19]. Besides existing in the nervous system, Kv7 also locates on smooth muscle[20], the skeletal muscle[21], and myoblast[22]. Meritxell Roura-Ferrer indicated that the potassium channel Kv7.5 is involved in myoblast cell proliferation[22]. Moreover, the recent study identified strong expression of Kv7.5 in the CCL-183 Canine Osteosarcoma Cell Line and examined the hypothesis that Kv7.5 is involved in the regulation of cancer cells[23]. Nevertheless, no study has focused on the relationship between variations in KCNQ5 and lung cancer.

In the present study, we evaluated the association between SNPs in KCNQ5 and the susceptibility of lung cancer in a northeast Chinese population, and the results of this study may contribute to the lung cancer screening in the future.

\section{MAterials AND Methods}

\section{Study subjects and data collection}

This hospital-based case-control study consisted of 833 lung cancer patients and 641 cancer-free controls. Patients were firstly confirmed as lung cancer by professional pathologists without previous chemotherapy or radiotherapy in the Fourth Affiliated Hospital of China Medical University. There were no gender or age restrictions. Meanwhile, controls were randomly recruited from the same hospital during the same period as frequency-matched cases according to age ( \pm 5 years), without lung cancer or lung cancer-related diseases. At the time of enrollment, each subject signed an informed consent form.

The data was collected from each subject in accordance with the following strict criterions: (i) $5 \mathrm{ml}$ blood sample was collected from each participant; (ii) each participant was questioned by welltrained interviewers under a standardized questionnaire including tobacco exposure and demographic information; (iii) the definition of smoking exposure. Smokers refer to people who consumed more than 100 cigarettes in the lifetime, otherwise are non-smokers. Approval of the investigations was obtained from the Institutional Review Board of China Medical University.

\section{DNA isolation and genotyping}

Genomic DNA samples were extracted from venous blood of all subjects by Phenol-chloroform exaction method. Genotyping of KCNQ5 rs4706511 and rs9293902 was conducted using Taqman allelic discrimination assay from Applied Biosystems(Foster City, CA, USA). Primers and probes 
were also purchased from Applied biosystems. The PCR conditions included $95^{\circ} \mathrm{c}$ for $10 \mathrm{~min}$, followed by 47 cycles of $92^{\circ} \mathrm{c}$ for 30s and $62^{\circ} \mathrm{c}$ for $1 \mathrm{~min}$. An Applied Biosystems 7500 FAST RealTime PCR System (Foster City, CA, USA) was used to read the reacted results. The duplicates of $10 \%$ randomly selected samples were tested a second time by another investigator, and the results were $100 \%$ consistent to the the duplicate sets for the quality control purpose.

\section{Statistical analysis}

All statistical analyses were performed with Statistical Product and Service Solutions (SPSS) v13.0. The $\chi^{2}$ test and Student's t-test were used to distinguish specific distribution of demographic variables and tobacco exposure between cases and controls. Hardy-Weinberg equilibrium (HWE) of the genotypes was tested by performing a goodness-of-fit $\chi^{2}$ test among controls. Unconditional logistic regression analysis was used to calculate the odds ratios (ORs) with 95\% confidence intervals (CIs) to evaluate associations of the SNPs with lung cancer. The stratified analyses were estimated by logistic regression models. All above analyses were adjusted by gender and age. All tests were two sided, and a value of $\mathrm{P}<0.05$ was considered statistical significant.

\section{Results}

\section{The studies' characteristics}

The collected demographic characteristics of 833 cases and 641 controls in the present study were listed in Table 1. Mean ages of cases (58.58 \pm 11.089 years) and controls (58.90 \pm 11.260 years) were almost identical, which was of no significant difference $(\mathrm{P}=0.899)$. There were significant differences in the distribution of gender and smoking status $(\mathrm{P}=0.005$ and $\mathrm{P}<0.001$, respectively). Cases consisted of 493 adenocarcinomas, 207 squamous cell carcinomas, 94 small-cell carcinoma and 39 other tumors including a variety of different pathologies (including large-cell, mixed cell carcinomas and undifferentiated carcinomas).

Table 1. Selected variables in cases and controls

\begin{tabular}{|c|c|c|c|c|}
\hline Variables & & Case $\mathbf{n}(\boldsymbol{\%})$ & control n(\%) & P value \\
\hline Gender & Male & 203 & 198 & $0.005^{\mathrm{b}}$ \\
\hline & Female & 630 & 443 & $0.899^{\mathrm{a}}$ \\
\hline Age & mean \pm SD & $58.58 \pm 11.089$ & $58.90 \pm 11.260$ & $0.000^{\mathrm{b}}$ \\
\hline Smoke & never & 652 & 570 & \\
\hline Histology & Yes & 172 & & \\
\hline & Adenocarcinoma & 493 & & \\
\hline & Small cell carcinoma & 207 & & \\
\hline & Squamous carcinoma & 94 & & \\
\hline
\end{tabular}

${ }^{\mathrm{a}} p$ value was calculated by the t-test; ${ }^{\mathrm{b}} p$ value was calculated by the chi-square test; Abbreviations: SD, standard deviation

\section{The association between SNP and lung cancer}

Table 2 presented the distribution of rs4706511 and rs9293902 genotypes in cases and controls. All allele distributions for two SNPs in the control were conformed to Hardy-Weinberg equilibrium $(\mathrm{P}>0.05)$. The $\mathrm{P}$ value of the minor allele frequencies (MAF) of rs4706511 and rs9293902 were 0.33 and 0.58, respectively. Individuals carrying GG genotype (adjusted $\mathrm{OR}=1.585,95 \% \mathrm{CI}=1.173-2.141$, $\mathrm{P}=0.003$ ) compared with AA genotype in rs4706511 showed a higher risk of lung cancer. CC genotype samples (adjusted $\mathrm{OR}=1.529,95 \% \mathrm{CI}=1.134-2.061, \mathrm{P}=0.005$ ) had an increased risk of lung cancer compared with TT genotype samples in rs9293902. Considering inevitable error caused by sample size, continuous analyses were conducted by combining the heterozygous variant genotype with the homozygous variant genotype in two SNPs. As expected, both AG/GG genotype carriers 
Association between Genetic Variations in Kv7.5 and Susceptibility of Lung Cancer in a Northeast Chinese Population

(adjusted $\mathrm{OR}=1.344,95 \% \mathrm{CI}=1.066-1.693, \mathrm{P}=0.012$ ) compared with AA genotype carriers and $\mathrm{CT} / \mathrm{CC}$ genotype carriers (adjusted $\mathrm{OR}=1.270,95 \% \mathrm{CI}=1.006-1.603, \mathrm{P}=0.045$ ) compared with $\mathrm{TT}$ genotype carriers indicated more risk of lung cancer.

Table 2. Genetic Polymorphisms and Lung Adenocarcinoma Risk

\begin{tabular}{|c|c|c|c|c|c|c|}
\hline SNP & Cases(\%) & Controls(\%) & $P$ of HWE & OR adj & $95 \%$ CI adj & $P$ value adj \\
\hline \multicolumn{7}{|l|}{ rs4706511 } \\
\hline AA & 205 & 195 & 0.43 & Ref & & \\
\hline $\mathrm{AG}$ & 428 & 326 & & 1.255 & $(0.984-1.602)$ & 0.068 \\
\hline GG & 200 & 120 & & 1.585 & $(1.173-2.141)$ & 0.003 \\
\hline $\mathrm{AG}+\mathrm{GG}$ & 628 & 446 & & 1.344 & $(1.066-1.693)$ & 0.012 \\
\hline A allele & 838 & 716 & & Ref & & \\
\hline $\mathrm{G}$ allele & 828 & 566 & & 1.249 & $(1.079-1.447)$ & 0.003 \\
\hline \multicolumn{7}{|l|}{ rs9293902 } \\
\hline TT & 204 & 187 & 0.36 & Ref & & \\
\hline $\mathrm{CT}$ & 420 & 329 & & 1.172 & $(0.916-1.499)$ & 0.207 \\
\hline $\mathrm{CC}$ & 209 & 125 & & 1.529 & $(1.134-2.061)$ & 0.005 \\
\hline $\mathrm{CT}+\mathrm{CC}$ & 629 & 454 & & 1.270 & $(1.006-1.603)$ & 0.045 \\
\hline $\mathrm{T}$ allele & 828 & 703 & & Ref & & \\
\hline $\mathrm{C}$ allele & 838 & 579 & & 1.227 & $(1.060-1.421)$ & 0.006 \\
\hline
\end{tabular}

$P$ adj is adjusted by age and gender.

\section{Stratified analysis}

Further analyses, stratified by histological type, were performed in table3. We found a distinct relationship between GG genotype and adenocarcinoma (adjusted $\mathrm{OR}=1.785,95 \% \mathrm{CI}=1.267-2.513$., $\mathrm{P}=0.001$ ) and small cell carcinoma (adjusted $\mathrm{OR}=2.228,95 \% \mathrm{CI}=1.175-4.223, \mathrm{P}=0.014$ ) in rs4706511. Analogously, similar results were observed in rs9293902 (for CC vs TT in adenocarcinoma: adjusted $\mathrm{OR}=1.744,95 \% \mathrm{CI}=1.241-2.452 ., \mathrm{P}=0.001$; for $\mathrm{CC}$ vs $\mathrm{TT}$ in small cell carcinoma: adjusted $\mathrm{OR}=2.171,95 \% \mathrm{CI}=1.150-4.096 ., \mathrm{P}=0.017)$. However, in squamous carcinoma, no statistically significant relationships were observed $(\mathrm{P}>0.05)$.

Table 3. The effect of the Genetic Polymorphism in the region on lung cancer risk in pathological subgroup

\begin{tabular}{|c|c|c|c|c|c|c|}
\hline SNP & & Cases(\%) & Controls (\%) & OR adj & $95 \%$ CI adj & $p$ value adj \\
\hline \multicolumn{7}{|l|}{ rs4706511 } \\
\hline \multirow[t]{3}{*}{ Adenocarcinoma } & $\mathrm{AA}$ & 124 & 195 & Ref & & \\
\hline & $\mathrm{AG}$ & 239 & 326 & 1.164 & $(0.876-1.548)$ & 0.296 \\
\hline & GG & 130 & 120 & 1.785 & $(1.267-2.513)$ & 0.001 \\
\hline \multirow[t]{3}{*}{ Squamous carcinoma } & $\mathrm{AA}$ & 51 & 195 & Ref & & \\
\hline & $\mathrm{AG}$ & 119 & 326 & 1.356 & $(0.930-1.978)$ & 0.114 \\
\hline & GG & 37 & 120 & 1.147 & $(0.705-1.867)$ & 0.581 \\
\hline \multirow[t]{3}{*}{ Small cell carcinoma } & $\mathrm{AA}$ & 20 & 195 & Ref & & \\
\hline & $\mathrm{AG}$ & 48 & 326 & 1.481 & $(0.847-2.591)$ & 0.169 \\
\hline & GG & 46 & 120 & 2.228 & $(1.175-4.223)$ & 0.014 \\
\hline \multicolumn{7}{|l|}{ rs9293902 } \\
\hline \multirow{3}{*}{ Adenocarcinoma } & TT & 122 & 187 & Ref & & \\
\hline & CT & 235 & 329 & 1.101 & $(0.826-1.469)$ & 0.512 \\
\hline & $\mathrm{CC}$ & 136 & 125 & 1.744 & $(1.241-2.452)$ & 0.001 \\
\hline \multirow[t]{3}{*}{ Squamous carcinoma } & TT & 52 & 187 & Ref & & \\
\hline & CT & 114 & 329 & 1.223 & $(0.837-1.785)$ & 0.298 \\
\hline & $\mathrm{CC}$ & 41 & 125 & 1.148 & $(0.715-1.845)$ & 0.567 \\
\hline \multirow[t]{3}{*}{ Small cell carcinoma } & TT & 20 & 187 & Ref & & \\
\hline & CT & 47 & 329 & 1.363 & $(0.777-2.389)$ & 0.280 \\
\hline & $\mathrm{CC}$ & 27 & 125 & 2.171 & $(1.150-4.096)$ & 0.017 \\
\hline
\end{tabular}

$P_{\text {adj }}$ is adjusted by age and gender. 
Association between Genetic Variations in Kv7.5 and Susceptibility of Lung Cancer in a Northeast Chinese Population

\section{Gene-environmental analysis}

In table 4, stratified by smoking exposure, we found that both GG genotype carriers (adjusted $\mathrm{OR}=1.719,95 \% \mathrm{CI}=1.227-2.408, \mathrm{P}=0.002$ ) compared with AA genotype carriers and $\mathrm{CC}$ genotype carriers (adjusted $\mathrm{OR}=1.712,95 \% \mathrm{CI}=1.223-2.394, \mathrm{P}=0.002$ ) compared with TT genotype carriers were more pronounced in increasing risk of lung cancer in no-smoking exposure. However, no statistically significant relationships were suggested in smoking exposure $(P>0.05)$.

Table 4. Genetic Polymorphisms in Relation to Risk of Lung cancer, Stratified by smoking Exposure

\begin{tabular}{|c|c|c|c|c|l|}
\hline SNP & Smoking & Cases(\%) & Controls(\%) & OR (95\% CI) adj & P value adj \\
\hline rs4706511 & & & & & \\
\hline AA & - & 157 & 171 & Ref & \\
\hline AG & - & 331 & 292 & $1.288(0.977-1.697)$ & 0.072 \\
\hline GG & - & 164 & 107 & $1.719(1.227-2.408)$ & 0.002 \\
\hline AA & + & 46 & 24 & Ref & \\
\hline AG & + & 90 & 34 & $1.439(0.751-2.757)$ & 0.273 \\
\hline GG & + & 36 & 13 & $1.752(0.769-3.994)$ & 0.182 \\
\hline rs9293902 & & & & & \\
\hline TT & - & 155 & 164 & $1.190(0.901-1.572)$ & 0.221 \\
\hline CT & - & 324 & 296 & $1.712(1.223-2.394)$ & 0.002 \\
\hline CC & - & 173 & 110 & Ref & \\
\hline TT & + & 47 & 23 & $1.443(0.747-2.789)$ & 0.275 \\
\hline CT & + & 90 & 33 & $1.389(0.622-3.105)$ & 0.423 \\
\hline CC & + & 35 & 15 & & \\
\hline
\end{tabular}

$P_{\text {adj }}$ is adjusted by age and gender.

\section{DISCUSSION}

In the present study, we investigated the relationship between the genetic polymorphism (Kv7.5rs4706511 and Kv7.5-rs9293902) and lung cancer risk in a Northeast Chinese population. After adjusted by age and gender, the results suggested that both GG genotype of rs4706511 and CC genotype of rs9293902 were closely associated with an increased risk of lung cancer, especially adenocarcinoma and small cell carcinoma. Considering that smoking exposure is a major environmental confounding factor for developing lung cancer, we performed the study stratified by smoking exposure. As a result, we found, stratified by smoking exposure, the relationships were more pronounced in no-smoking populations. However, there were no statistically significant results in smoking populations. One of the reasons may be that the expected results could be obscured by smoking exposure factor. Furthermore, because the functional significance of kv7.5 is not clear and the molecular mechanism of the genetic locus remains elusive, additional larger studies are needed to certify our findings.

To our knowledge, the molecular study of lung cancer becomes increasingly popular all over the world these years. Voltage-gated potassium (Kv) channels become increasingly important among the most diverse ion channel families as the development of patch clamp technology and the application of tumor cell membrane ion channels. In recent years, researchers have done their best to explore the potential role of $\mathrm{Kv}$ channels, however, the molecular mechanism and exact function remains indistinct. The latest probable explanation is that non-conducting mechanism contribute to proliferation rather than ion-flux mechanism[24]. Previous studies manifested for the first time that Kv1.3 and Kv1.5 are altered during smooth muscle carcinogenesis and showed that the increased expression of K1.3 and Kv1.5 prompt leiomyosarcoma aggressiveness[25]. Likewise, the result of previous study demonstrated that the specific knockdown of Kv9.3 decrease proliferation in human colon and lung carcinoma cells[26]. Moreover, many recent studies also indicated that the abnormal 
expression of potassium channel correlates with the occurrence, proliferation and invasion of cancer cells[27-29] .

Recently, a study conducted by Bo Hyung Lee for the first time identified Kv7.5 in the CCL-183 Canine Osteosarcoma Cell Line and also demonstrated its anti-proliferative effect by upregulate kv7.5[23]. Though the conclusion resulted from animal cell test, it provides significant biologically credible evidence to that kv7.5 is involved in the proliferation of cancer. Moreover, Bo Hyung Lee also revealed that Sp1 plays a important role in the regulation of Kv7.5 expression[23]. Similarly, we deemed the genetic variation in Kv7.5 as the alternative primary factor determining self expression. In the present study, we found that GG genotype increase the risk of lung cancer in rs 4706511 compared with AA genotype and CC genotype indicates more risk of lung cancer in rs9293902 in comparison with TT genotype. Though the exact molecular mechanism of Kv7.5 is still unclear, the results of the study provided clue for further study of Kv7.5.

Up till now, it is the first time to conduct molecular epidemiological study among the entire population to evaluate the correlation between Kv7.5 gene polymorphisms and lung cancer risk. The superiority of this study is its accuracy of data collections, as all the information were collected by well-trained interviewers, and all the cases were confirmed by professional pathologists. And the newly-diagnosed patients were selected as the cases, which could effectively avoid the Neyman bias. However, some limitations may exist in the present study. There are some environmental factors that, such as passive smoking, may not be considered.

In recent years, the Kv7 family is a newly emerging research focus on molecular epidemiology and as Kv7.5 has become the latest family member to be investigated, further studies are required to analyze relationships between alternative diverse genetic locus and susceptibility of lung cancer and evaluate its roles in development, proliferation and metastasis of lung cancer.

In conclusion, our study revealed that polymorphisms in KCNQ5 (rs4736511 and rs9293902) may increase the risk of lung cancer in a northeast Chinese population.

\section{ACKNOWLEDGEMENTS AND FUNDING}

This study was supported by grant no.81502878 from Youth Fund Project of National Natural Science Foundation of China and grant no.201501017 from Dr Research Start-up Fund Project of liaoning province. Thanks for the efforts of all the authors.

\section{REFERENCES}

[1] Parkin DM, Bray F, Ferlay J, Pisani P. Global cancer statistics, 2002. Ca A Cancer Journal for Clinicians. 2005; 55: 74.

[2] Brennan P, Hainaut P, Boffetta P. Genetics of lung-cancer susceptibility. Lancet Oncology. 2011; 12: 399408.

[3] Ferlay J, Soerjomataram I, Dikshit R, Eser S, Mathers C, Rebelo M, Parkin DM, Forman D, Bray F. Cancer incidence and mortality worldwide: Sources, methods and major patterns in GLOBOCAN 2012. International Journal of Cancer. 2015; 136: E359.

[4] Lang F, Gulbins E, Szabo I, Lepple-Wienhues A, Huber SM, Duranton C, Lang KS, Lang PA, Wieder T. Cell volume and the regulation of apoptotic cell death. Journal of Molecular Recognition Jmr. 2004; 17: 473.

[5] Lee SY, Maniak PJ, Ingbar DH, O'Grady SM. Adult alveolar epithelial cells express multiple subtypes of voltage-gated $\mathrm{K}+$ channels that are located in apical membrane. American Journal of Physiology Cell Physiology. 2003; 284: 1614-24.

[6] Lotz MM, Wang AH, Ms BJCS, Pories CSE, c aJBMM. K + channel inhibition accelerates intestinal 
epithelial cell wound healing. Wound Repair \& Regeneration. 2004; 12: 565-74.

[7] O’Grady SM, Lee SY. Molecular diversity and function of voltage-gated (Kv) potassium channels in epithelial cells. International Journal of Biochemistry \& Cell Biology. 2005; 37: 1578-94.

[8] Ouadidahidouch H, Chaussade F, Roudbaraki M, Slomianny C, Dewailly E, Delcourt P, Prevarskaya N. $\mathrm{KV} 1.1 \mathrm{~K}(+)$ channels identification in human breast carcinoma cells: involvement in cell proliferation. Biochemical \& Biophysical Research Communications. 2000; 278: 272.

[9] Pardo LA. Voltage-gated potassium channels in cell proliferation. Physiology. 2004; 19: 285.

[10] Rao JN, Platoshyn O, Li L, Guo X, Golovina VA, Yuan JX, Wang JY. Activation of K(+) channels and increased migration of differentiated intestinal epithelial cells after wounding. American Journal of Physiology Cell Physiology. 2002; 282: C885.

[11] Thun MJ, Henley SJ, Burns D, Jemal A, Shanks TG, Calle EE. Lung cancer death rates in lifelong nonsmokers. J Natl Cancer Inst. 2006; 98: 691-9.

[12] Yu FH, Catterall WA. The VGL-chanome: a protein superfamily specialized for electrical signaling and ionic homeostasis. Sciences Stke Signal Transduction Knowledge Environment. 2004; 2004: re15.

[13] Leblanc N. Kv3.4, a key signalling molecule controlling the cell cycle and proliferation of human arterial smooth muscle cells. Cardiovascular Research. 2010; 86: 351.

[14] Kim HJ, Jang SH, Jeong YA, Ryu PD, Kim DY, Lee SY. Involvement of Kv4.1 K(+) channels in gastric cancer cell proliferation. Biological \& Pharmaceutical Bulletin. 2010; 33: 1754-7.

[15] Jin W, Zhida C, Qingjun L, Wenrong Z, Xinyu W, Bin L. Silencing of Kv1.5 Gene Inhibits Proliferation and Induces Apoptosis of Osteosarcoma Cells. International Journal of Molecular Sciences. 2015; 16: 26914-26.

[16] Jiménez-Pérez L, Cidad P, I Á-M, Santos-Hipólito A, Torres-Merino R, Alonso E, Má DLF, López-López JR, Pérez-García MT. Molecular Determinants of Kv1.3 Potassium Channels-induced Proliferation. Journal of Biological Chemistry. 2016; 291: 3569.

[17] Min SS, Choi SY, Pan DR, Lee SY. Voltage-Gated K+ Channel, Kv3.3 Is Involved in Hemin-Induced K562 Differentiation. Plos One. 2016; 11: e0148633.

[18] Andersen MN, Krzystanek K, Petersen F, Bomholtz SH, Olesen SP, Abriel H, Jespersen T, Rasmussen HB. A phosphoinositide 3-kinase (PI3K)-serum- and glucocorticoid-inducible kinase 1 (SGK1) pathway promotes Kv7.1 channel surface expression by inhibiting Nedd4-2 protein. Journal of Biological Chemistry. 2013; 288: 36841-54.

[19] Robbins J. KCNQ potassium channels: physiology, pathophysiology, and pharmacology. Pharmacology \& Therapeutics. 2001; 90: 1-19.

[20] Haick JM, Brueggemann LI, Cribbs LL, Denning MF, Schwartz J, Byron KL. PKC-DEPENDENT REGULATION OF Kv7.5 CHANNELS BY THE BRONCHOCONSTRICTOR HISTAMINE IN HUMAN AIRWAY SMOOTH MUSCLE CELLS. Am J Physiol Lung Cell Mol Physiol. 2017; 312 : ajplung.00567.2016.

[21] Zagorchev P, Apostolova E, Kokova V, Peychev L. Activation of KCNQ channels located on the skeletal muscle membrane by retigabine and its influence on the maximal muscle force in rat muscle strips. Naunyn Schmiedebergs Arch Pharmacol. 2016; 389: 439-46.

[22] Roura-Ferrer M, Solé L, Martínez-Mármol R, Villalonga N, Felipe A. Skeletal muscle Kv7 (KCNQ) channels in myoblast differentiation and proliferation. Biochemical \& Biophysical Research Communications. 2008; 369: 1094-7.

[23] Lee BH, Ryu PD, Lee SY. Serum starvation-induced voltage-gated potassium channel Kv7.5 expression and its regulation by Sp1 in canine osteosarcoma cells. International Journal of Molecular Sciences. 2014; 15: 977.

[24] Cidad P, Jiménez-Pérez L, García-Arribas D, Miguel-Velado E, Tajada S, Ruiz-Mcdavitt C, López-López 
JR, Pérez-García MT. Kv1.3 channels can modulate cell proliferation during phenotypic switch by an ionflux independent mechanism. Arteriosclerosis Thrombosis \& Vascular Biology. 2012; 32: 1299.

[25] Bielanska J, Hernándezlosa J, Moline T, Somoza R, Cajal SRY, Condom E, Ferreres JC, Felipe A. Increased voltage-dependent $\mathrm{K}+$ channel Kv1.3 and Kv1.5 expression correlates with leiomyosarcoma aggressiveness. Oncology Letters. 2012; 4: 227-30.

[26] Lee JH, Park JW, Byun JK, Kim HK, Pan DR, Lee SY, Kim DY. Silencing of voltage-gated potassium channel KV9.3 inhibits proliferation in human colon and lung carcinoma cells. Oncotarget. 2015; 6: 8132.

[27] Wang R, Cai BH, Xiang J, Zhu XW, Jiang Y. [Expression of voltage-gated potassium channel Kv3.4 in oral squamous cell carcinoma]. Zhonghua kou qiang yi xue za zhi = Zhonghua kouqiang yixue zazhi = Chinese journal of stomatology. 2016; 51: 137.

[28] He T, Wang C, Zhang M, Zhang X, Zheng S, Linghu E, Guo M. Epigenetic regulation of voltage-gated potassium ion channel molecule Kv1.3 in mechanisms of colorectal cancer. Discovery Medicine. 2017; 23: 155 .

[29] Jang SH, Choi C, Hong SG, Yarishkin OV, Bae YM, Kim JG, O'Grady SM, Yoon KA, Kang KS, Ryu PD. Silencing of Kv4.1 potassium channels inhibits cell proliferation of tumorigenic human mammary epithelial cells. Biochemical \& Biophysical Research Communications. 2009; 384: 180-6.

Citation: H. Zhang et al., " Association between Genetic Variations in Kv7.5 and Susceptibility of Lung Cancer in a Northeast Chinese Population ", International Journal of Research in Environmental Science, vol. 4, no. 1, p. 39-46, 2018. http://dx.doi.org/ 10.20431/2454-9444.0401005

Copyright: (C) 2018 Authors. This is an open-access article distributed under the terms of the Creative Commons Attribution License, which permits unrestricted use, distribution, and reproduction in any medium, provided the original author and source are credited. 